\title{
Monitoring and Control of Distribution Transformer
}

\author{
P.Maithili, Mathankumar.A, Dinesh.L, Vijayakumar
}

\begin{abstract}
This paper gives the solution on monitoring and control of distribution transformer efficiently. At present, during fault in lines the transformer is turned off manually to rectify the fault and requires two field workers. Here we developed a wireless controlling system to open or close the transformer. The opening and closing of the transformer is confirmed by using CT (current transformer) and PT (potential transformer) measuring instrument. The data of the measuring instruments are sent through GSM (global system for mobile communication) to the EB officials and it requires only one field worker at the faulty location. The main feature of this paper is the field worker can be reduced, accident occurring due to back current at the time when the field worker work at the line can be reduced and the transformer switch can be controlled at remote location. This paper leads to the safety working of the field workers.
\end{abstract}

Key words: Pulse Width Modulation, Potential Transformer, Current Transformer, GSM

\section{INTRODUCTION}

The methods that practically used now in TNEB (Tamil Nadu Electricity board) when abnormal condition in the distribution line are they call upon the line man to climb up the post to rectify any of the fault mistakes. Before climbing in the post he or another line man first goes to the distribution transformer and should turn off all three phases by using the disc pole switch by using supporting rod which is also carried by the line man. After turning off the transformer the line man on the fault side climbs the post and start rectifying it but there is time when improper or faulty condition UPS (uninterrupted power supply) fail to hold the battery power and at times where it returns back current to the supply lines hence the line man get shocked and accident occur.

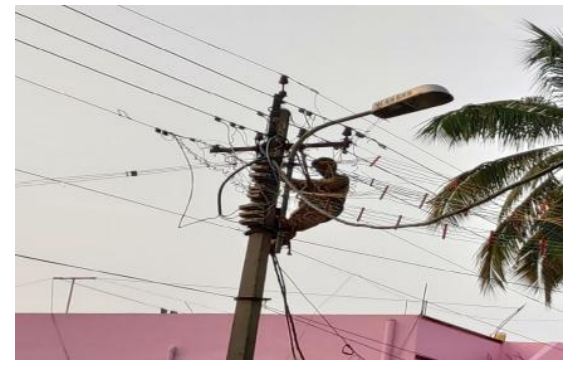

Fig 1.1 Line man working in the post

Revised Manuscript Received on August 14, 2019.

P.Maithili, Assistant Professor, Department of EEE Kumaraguru College of Technology, Coimbatore India. (E-mail: maithili.p.eee@kct.ac.in)

Mathankumar.A, UG Student Department of EEE Kumaraguru College of Technology, Coimbatore India.

Dinesh.L, UG Student Department of EEE Kumaraguru College of Technology, Coimbatore India.

Vijayakumar, UG Student Department of EEE Kumaraguru College of Technology, Coimbatore India.

\section{BLOCK DIAGRAM:}

The overall block diagram of the system is shown in fig 2.1. It consists of current and potential transformer with GSM module. The micro controller is used to control the gear motor.

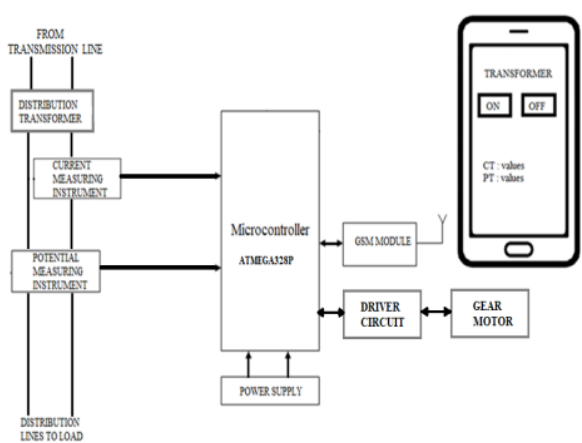

Fig 2.1 Block diagram

2.2: Hardware Circuit Configuration

\subsubsection{POWER SUPPLY CIRCUIT:}

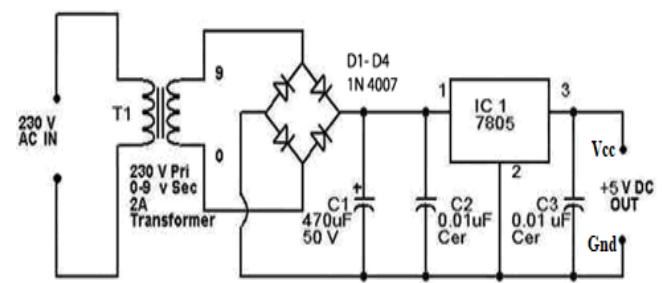

Fig 2.2 Power Supply Circuit Configuration

The above figure shows the output pin of the Power supply is connected to the VCC and GND. The single phase AC supply is step down to a $0-9 \mathrm{v} A C$ and the output is given to bridge rectifier to convert it to pulsating DC and the pulsating voltage is made to constant by the voltage regulator.

\subsubsection{GSM MODULE}

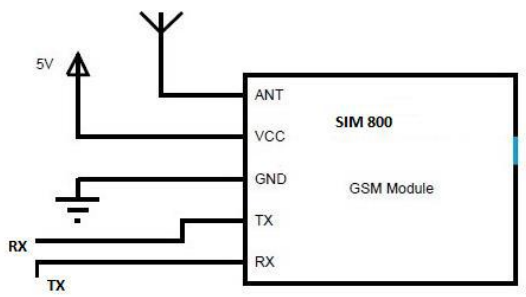

Fig 2.3 GSM Module Configuration 
The above figure shows the output pin of the GSM, RX is connected to the TX and the TX is connected to the RX. SIM800 is a complete Quad-band GSM/GPRS solution in a SMT type which can be embedded in the customer applications.

SIM800 support Quad-band 850/900/1800/1900MHz, it can transmit Voice, SMS and data information with low power consumption. With tiny size of $24 * 24 * 3 \mathrm{~mm}$, it can fit into slim and compact demands of customer design.

\subsubsection{POTENTIAL SENSOR (ZMPT1O1B):}

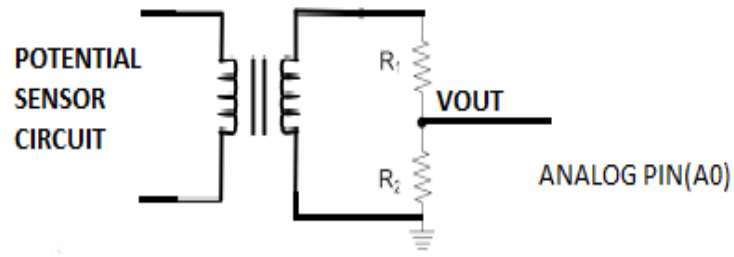

Fig 2.4 Potential Sensor Configuration

The above figure shows the output pin of the PT is connected to the analog pin (A0). ZMPT101B, a voltage transformer ideal to measure the $\mathrm{AC}$ voltage. It has high accuracy, good consistency for voltage and power measurement and it can measure up to $250 \mathrm{~V}$ AC. It is simple to use and comes with a multi turn trim potentiometer for adjusting the ADC output.

\subsubsection{CURRENT SENSOR (ZMCT103C):}

The above figure shows the output pin of the CT is connected to the analog pin (A1). A current transformer (CT) is used for measurement of alternating electric currents.

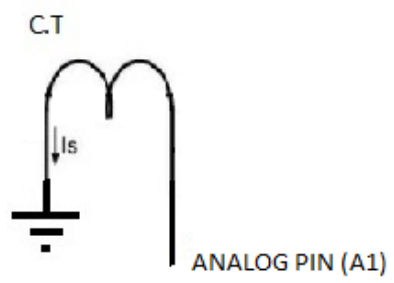

Fig 2.5 Current Sensor Configuration

When current in a circuit is too high to apply directly to measuring instruments, a current transformer produces a reduced current accurately proportional to the current in the circuit, which can be conveniently connected to measuring and recording instruments. A current transformer isolates the measuring instruments from what may be very high current in the monitored circuit.

\subsubsection{DRIVER CIRCUIT (L293D):}

The figure 2.5 shows the output pin of the Motor driver (E1) is connected to the digital pin (D8) and E2 is connected to the digital pin (D9).

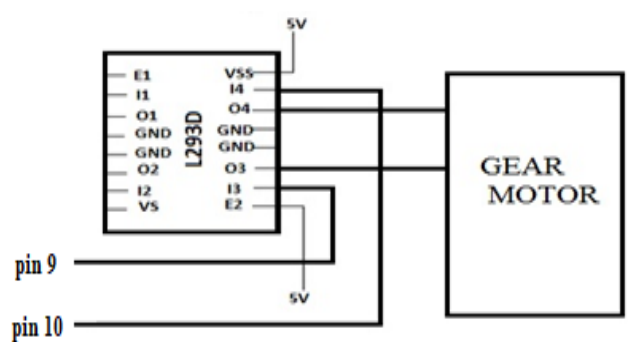

Fig 2.5 Driver Circuit Pin Configuration

L293D is a typical Motor driver or Motor Driver IC which allows DC motor to drive on either direction. L293D is a 16-pin IC which can control a set of two DC motors simultaneously in any direction. It means that you can control two DC motor with a single L293D IC.

\subsection{CIRCUIT DIAGRAM}

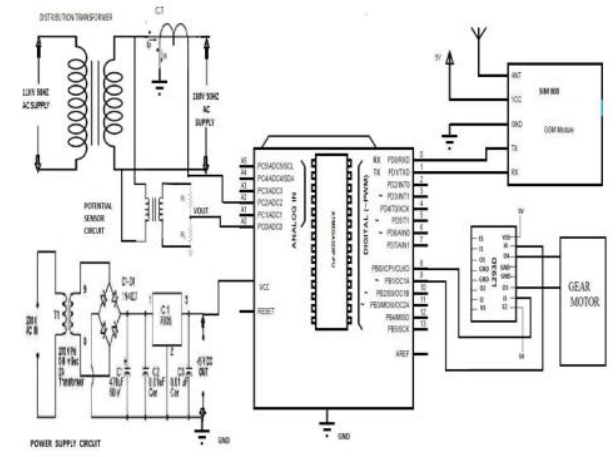

Fig 2.6 Circuit diagram

\subsection{DESCRIPTION:}

At present, during fault in lines the transformer is turned off manually to rectify the fault and requires two field workers. Here we used wireless controlling system to open or close the transformer.

During fault condition E.B worker just sent a SMS to GSM to turn OFF the transformer. Now the transformer turns OFF which is confirmed by the CT and PT sensor that measures the status of the device and sent to the worker mobile when current and voltage value is zero. Now the worker is confirmed the doesn't current falls in the distribution line. And the worker cleared the fault and then sent another SMS to the GSM to turn ON the transformer. And the worker receives a C.T value.

The opening and closing of the transformer is confirmed by using CT (current transformer) and PT (potential transformer) measuring instrument. The data of the measuring instruments are sent through GSM (global system for mobile communication) to the EB officials and it requires only one field worker at the faulty location.

The advantage of this project is the field worker can be reduced, accident occurring due to back current at the time when the field worker work at the line can be reduced and the transformer switch can be controlled at remote location. Thus our project leads to the safety working of the field workers. 


\section{METHODOLOGY:}

\subsection{FLOW CHART}

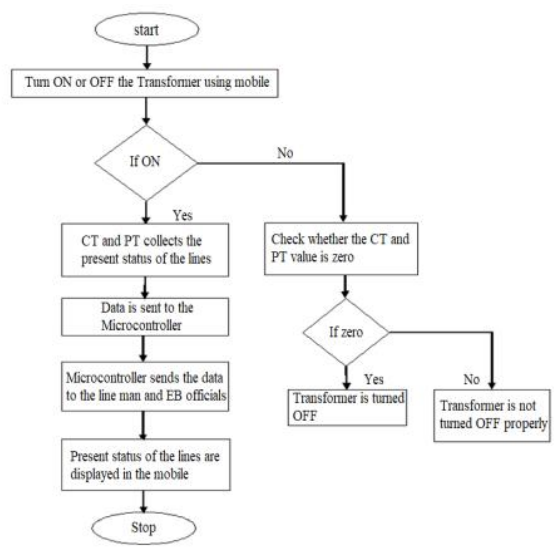

Fig 3.1 Flow Chart

\subsection{IMPLEMENTATION}

At present the existing project consisting of transformer harmonics reduction and improving the efficiency. The transformer consisting of buchholz relay for monitoring the internal fault and the amount of oil present in the tank of conservator. Also the manual operation is done on the transformer like checking the oil. The motor control for isolator and relay for circuit breaker is presently available in the substation. 18

This paper deals with hardware which is implemented with current sensor for measuring the active current values in the line of secondary side of the distribution transformer on all the three phases and the values are send to corresponding field workers and the electrical professionals, voltage sensor are used to measure each phase voltage of the transformer on secondary side of the distribution transformer and send to the corresponding electrical officials, GSM module which is used to send the data via the SMS under the command of microcontroller, gear motor for opening and closing of the distribution transformer,

\section{RESULT AND DISCUSSION}

\subsection{Hardware description:}

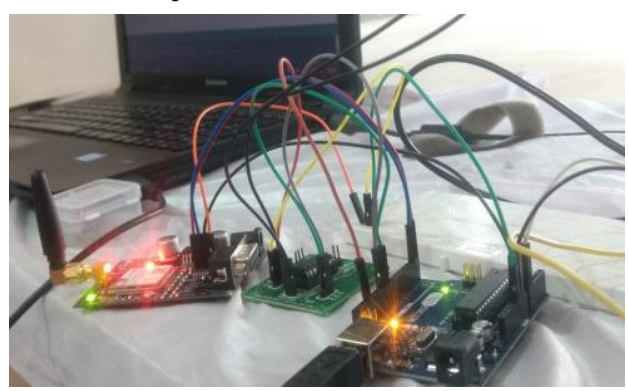

Fig 4.1 Overall Hardware Diagram

\subsection{System Specifications}

\begin{tabular}{|l|l|}
\hline Componentsname & Model \\
\hline Current sensor & Zmct103c \\
\hline Potential sensor & Zmpt101b \\
\hline Gsm module & Sim 800 \\
\hline
\end{tabular}

\begin{tabular}{|l|l|}
\hline Microcontroller & Atmega 328 \\
\hline Power supply circuit & Ac - dc \\
\hline Motor driver & L293d \\
\hline
\end{tabular}

Table 4.1 Specification

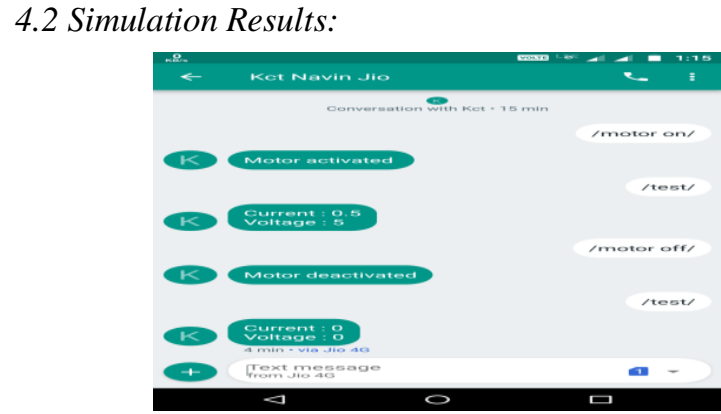

Fig 4.1 Results of GSM

\section{CONCLUSION:}

This paper the entire protection system for Electricity board people have been implemented we can ensure the safety of the workers those who are operating on transmission lines and also we can save time to rectify the fault.

\subsection{FUTURE SCOPE:}

In future to add the thermoelectric generator is used to power source to the microcontroller. Thermoelectric generator is placed in between the heat sink of transformer which the produces the thermal energy is converted to electrical energy by using thermoelectric generator.

\section{REFERENCES}

1. Armando Guzman, Normann Fischer, Casper Labuschagne. "Improvements in transformer protection and control" 2009 ,62nd Annual Conference for Protective Relay Engineers IEEE 2009

2. J.m. sketchley "the role of transformer oil analysis in the detection of fault conditions" iee colloquium on assessment of degradation within transformer insulation systems, IEEE 2002.

3. P.N. jarman"transformer winding movement and faultdetection" iee colloquium on assessment of degradation within transformer insulation systems IEEE 2006.

4. https://www.engineeringtoolbox.com/heat-gain-equipmentd_1668.html

5. https://www.engineersgarage.com/articles/gsm-gprs-modules

6. https://www.electricaleasy.com/2014/06/instrumenttransformers-ct-and-pt.html 